NBER WORKING PAPER SERIES

\title{
BANKRUPTCY RATES AMONG NFL PLAYERS WITH SHORT-LIVED INCOME SPIKES
}

\author{
Kyle Carlson \\ Joshua Kim \\ Annamaria Lusardi \\ Colin F. Camerer \\ Working Paper 21085 \\ http://www.nber.org/papers/w21085 \\ NATIONAL BUREAU OF ECONOMIC RESEARCH \\ 1050 Massachusetts Avenue \\ Cambridge, MA 02138 \\ April 2015
}

Camerer thanks the MacArthur Foundation and the BNDF (Caltech). We also thank Zach Fein and Stephen Loesch for careful research assistance. The views expressed herein are those of the authors and do not necessarily reflect the views of the National Bureau of Economic Research.

NBER working papers are circulated for discussion and comment purposes. They have not been peerreviewed or been subject to the review by the NBER Board of Directors that accompanies official NBER publications.

(C) 2015 by Kyle Carlson, Joshua Kim, Annamaria Lusardi, and Colin F. Camerer. All rights reserved. Short sections of text, not to exceed two paragraphs, may be quoted without explicit permission provided that full credit, including $(\odot)$ notice, is given to the source. 
Bankruptcy Rates among NFL Players with Short-Lived Income Spikes

Kyle Carlson, Joshua Kim, Annamaria Lusardi, and Colin F. Camerer

NBER Working Paper No. 21085

April 2015

JEL No. D91

\begin{abstract}
$\underline{\text { ABSTRACT }}$
One of the central predictions of the life cycle hypothesis is that individuals smooth consumption over their economic life cycle; thus, they save when income is high, in order to provide for when income is likely to be low, such as after retirement. We test this prediction in a group of people-players in the National Football League (NFL) — whose income profile does not just gradually rise then fall, as it does for most workers, but rather has a very large spike lasting only a few years. We collected data on all players drafted by NFL teams from 1996 to 2003. Given the difficulty of directly measuring consumption of NFL players, we test whether they have adequate savings by counting how many retired $\mathbb{N} F L$ players file for bankruptcy. Contrary to the life-cycle model predictions, we find that initial bankruptcylfilings begin very soon after retirement and continue at a substantial rate through at least the first 12 lyears of retirement. Moreover, bankruptcy rates are not affected by a player's total earnings or careerllength. Having played for a long time and been well-paid does not provide much protection againstlthe risk of going bankrupt.
\end{abstract}

Kyle Carlson

California Institute of Technology

1200 E. Calif. Blvd.

Pasadena, CA 91125

kcarlson@caltech.edu

Joshua Kim

University of Washington

33105 49th Ave SW

Federal Way, WA 98023

joshuak2@uw.edu

\author{
Annamaria Lusardi \\ The George Washington University \\ School of Business \\ 2201 G Street, NW \\ Duques Hall, Suite 450E \\ Washington, DC 20052 \\ and NBER \\ alusardi@gwu.edu \\ Colin F. Camerer \\ Department of Economics \\ California Institute of Technology \\ Pasadena, CA 91125 \\ camerer@hss.caltech.edu
}




\section{Introduction}

One of the central predictions of the life-cycle hypothesis is that individuals smooth consumption over their economic life cycle; thus, they save when income is high to provide for when income is likely to be low, such as after retirement.

We test for consumption smoothing in a group of people whose income profile does not just gradually rise then fall, as it does for most workers, but rather has a very large spike lasting only a few years. These people are players in the National Football League (NFL). A career lasting 6 years (the median length) will provide an NFL player with more earnings than an average college graduate will get in an entire lifetime, plus a modest pension (Figure 1). However, earnings are risky because an injury can cut a player's career short. Even healthy players' careers usually end by their mid-30s. Players' typical post-retirement income is much lower than the income they earn while playing, and NFL retirement benefits are modest (Weir, Jackson and Sonnega, 2009). These features of income level and uncertainty are presumably known to players. To maintain a smooth level of consumption after the predictable post-NFL income drop, a rational, patient player should therefore save a large portion of his NFL earnings and enter retirement with a high net worth.

It is difficult to measure the ups and downs of the consumption and wealth of NFL players. Therefore, to test whether NFL players have adequate savings we measure how many retired NFL players file for bankruptcy.

In simulations not reported here, benchmark forecasts of optimallysaving individuals with income spikes, calibrated to what the NFL players actually earn, yield essentially no simulated bankruptcies (based on Livshits, MacGee and Tertilt, 2007). However, NFL players may not save enough because of optimism about career length, poor financial decisions, or social pressures to spend (factors we will consider in ongoing work).

Indeed, we find that initial bankruptcy filings begin to occur very soon after retirement and continue at a substantial rate through at least the first 12 years of retirement. 


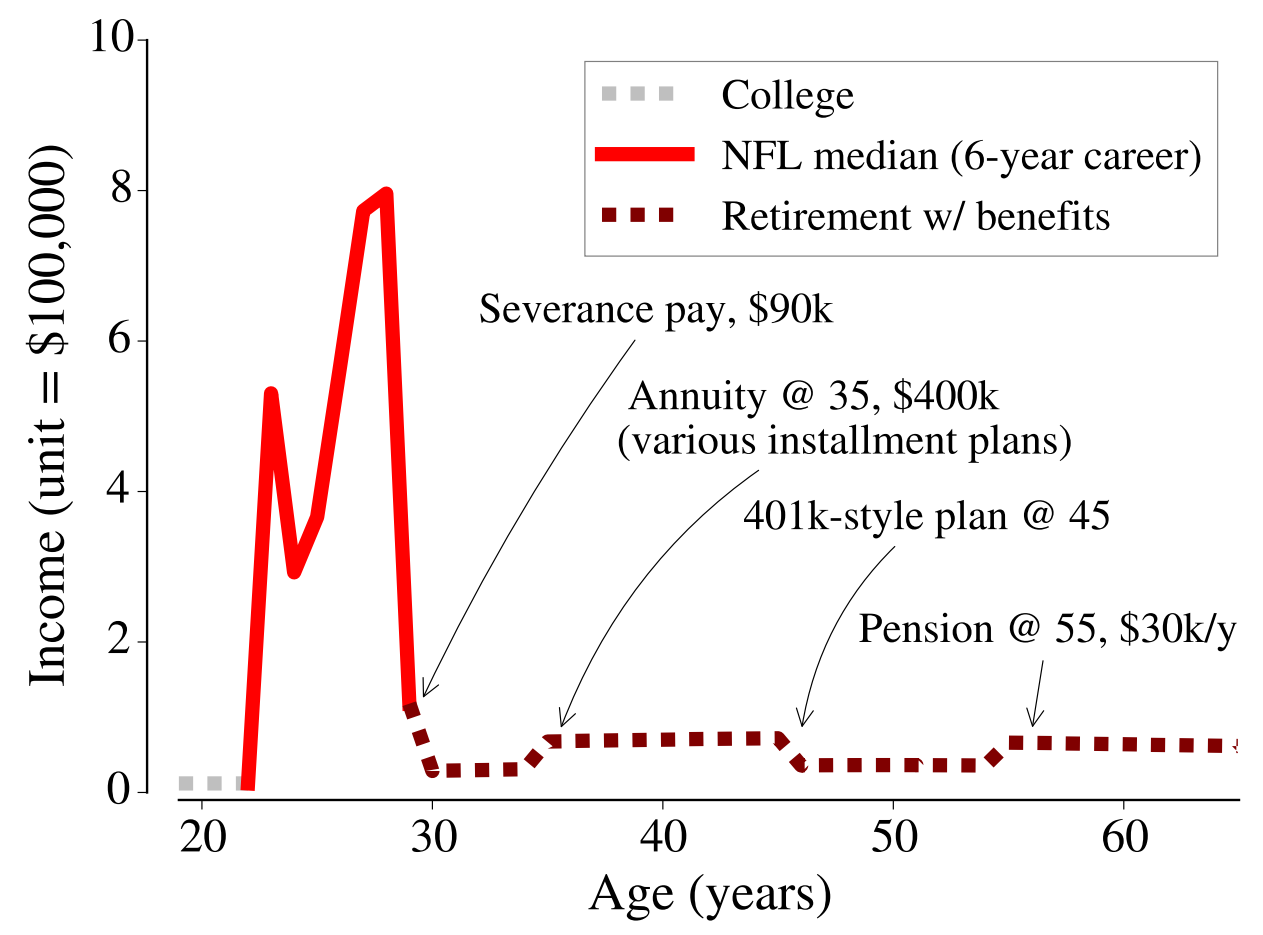

Figure 1: STYLIZED tyPiCAL NFL INCOME PROFILE (MEDiAn EARNings FOR A MEDIAN-LENGTH CAREER)

\section{Data sources}

We collected data on all players drafted by NFL teams from 1996 to 2003 $(N=2,016) .{ }^{1}$ NFL players are public figures so information about them is available from many sources. We used pro-football-reference.com and NFL.com to obtain basic information, including full name, career length, date of birth, hometown, and college. Annual NFL salary information was sourced from USAToday.com and Spotrac.com. Salary data is only available starting in the year 2000, so career earnings could only be calculated for

\footnotetext{
${ }^{1}$ In the annual draft, teams sequentially pick rookie players. However, a total of 134 of the draftees did not play in the NFL. They are omitted from most analyses but including them as retired players makes little difference. Another 79 players played to the 2013 season or later; their retirement periods did not overlap with our bankruptcy data. They are still included in our analyses whenever possible.
} 


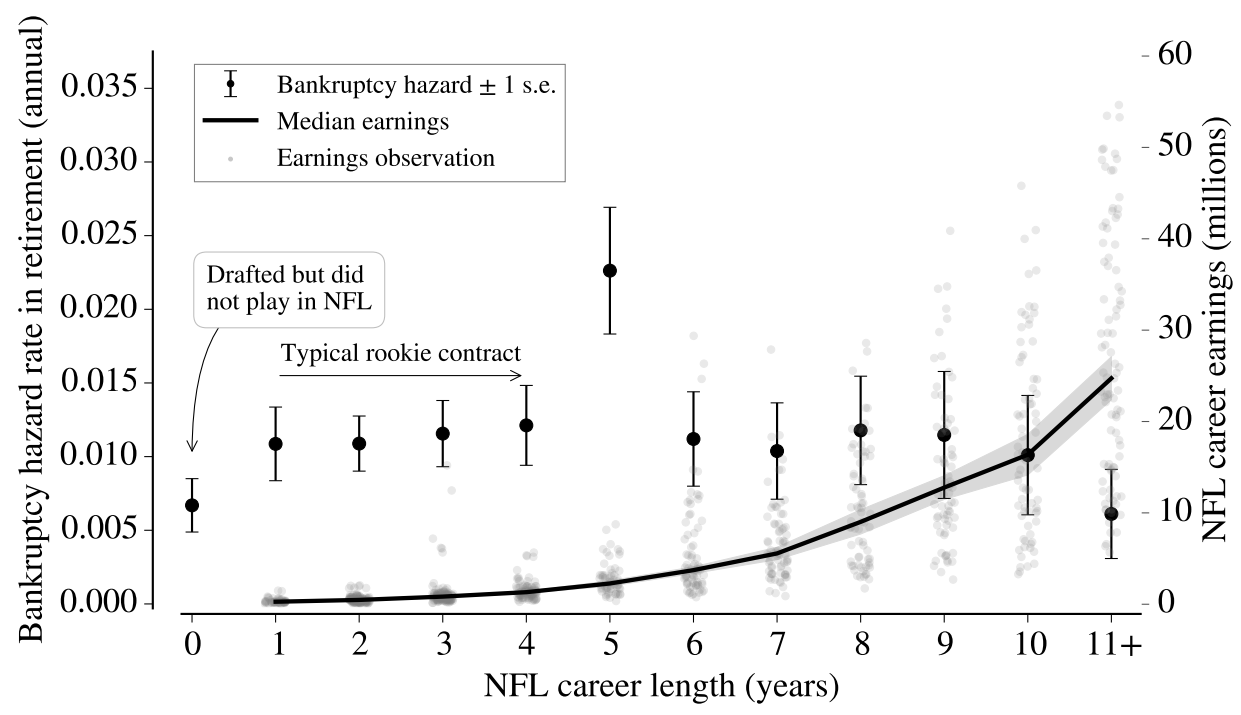

Figure 2: BANKRUPtCY HAZARD RATES By CAREER LENGTH

players whose entire careers began and ended between 2000 and 2013. There were 928 such players and 892 of them had earnings data available. To check the quality of the salary data we regressed log career earnings on career length interacted with draft round dummy variables. The regression has an $R^{2}$ of 0.83 and the expected coefficients on all variables. Bankruptcy court documents are public information, so we used a commercial background check service to search for filings by the players. Individuals were matched to bankruptcy records by full name and address. Matches were carefully inspected to rule out false positives.

The performance of the matching process is good; for example, we find very few filings by individuals while they are still playing, but many filings among the retired.

\section{Bankruptcies}

We describe bankruptcies in terms of the annual hazard rate of the time to the first bankruptcy filing. Very few players file for bankruptcy before 
retirement, which makes a survival analysis focusing on retirement appropriate. $^{2}$ This approach also deals well with the varying lengths of different players' retirement periods. The sample is censored after 2013 due to data availability.

In Figure 2, bankruptcy hazard rates and median career earnings are shown for each career length bin. Each player's total career earnings are plotted with jitter. The median level of earnings across all players is about $\$ 3.2$ million (in year 2000 dollars). The figure shows that players with longer careers have much greater earnings and opportunity to save for retirement, yet their bankruptcy hazard during retirement is no lower than those with shorter careers and lower earnings (the hazard rate is roughly constant). Among individuals who played at least one season, the average annual hazard rate during retirement (with standard error) is $0.0119 \pm 0.0009$. These rates are remarkably flat across career lengths, except for a pronounced spike for players who played exactly 5 years (one year beyond the typical 4 -year rookie contract). This spike will be investigated in future research.

Table 1 shows estimates of bankruptcy hazard functions. Each row of the table corresponds to a separate regression, including a different "career variable" measure and a common "being retired" 0-1 dummy in each regression. The last column shows that the estimated effect of being retired is to increase the annual hazard rate by about 0.01123 in model (1), and is similarly close to 0.01 in all specifications. Essentially, retirement raises the risk of bankruptcy from nearly zero to a substantial level. These estimates are robust to the inclusion of additional variables that are expected to affect bankruptcy risk. The "career variable" column in Table 1 shows the estimated effects of the variables listed in the second column of the table. These variables are interacted with a retirement dummy variable in order to isolate the retirement period, where almost all bankruptcies occur.

\footnotetext{
${ }^{2}$ We estimate discrete-time hazard functions using linear probability models. These regressions use data where each player contributes one observation for each month from the time he starts playing until he files for bankruptcy or reaches the end of the time period when we have data available. The outcome is 1 in the last month if bankruptcy is filed and 0 otherwise. A player's retirement period is defined as starting in January of year $y+1$ if his final NFL season was in year $y$.
} 


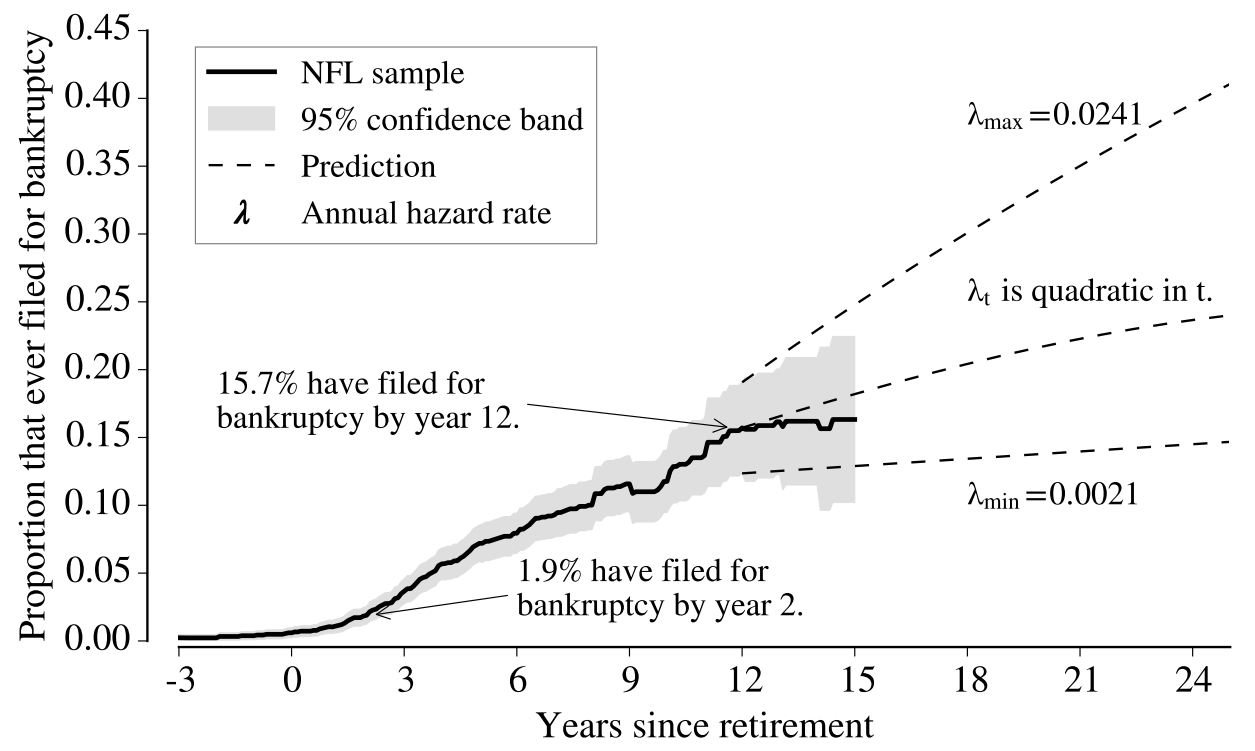

Figure 3: Evolution of BANKRUPtCy RATES DURING RETIREMENT

There are no significant effects of career earnings or career length on the bankruptcy hazard rate. An additional $\$ 1$ million in career earnings is estimated to reduce the hazard rate by only $0.000034 \pm 0.000183$. Small, insignificant effects are also found for all other career variables listed in column 2.

These earnings models include only half the sample because of limits on salary data availability. However, the full sample is used in a regression where career length serves as a proxy for career earnings (row 2). Each additional year in the NFL is estimated to decrease bankruptcy hazard during retirement by a minuscule $0.00017 \pm 0.00027$.

We note that increased career earnings do reduce bankruptcy very early in retirement, but the effect is quite small. (In all post-retirement spans longer than two years, there is no significant effect of higher earnings on bankruptcy hazard.) In the two-years-only model an extra $\$ 1$ million in earnings decreases the bankruptcy hazard rate by $0.000305 \pm 0.000125$. To put this effect in context, note that in the same two-years-only model retire- 
Table 1: EfFects of CAREER Length, EARnings, And RETIREMENT on THE BANKRUPTCY HAZARD RATE

\begin{tabular}{llcc}
\hline & & \multicolumn{2}{c}{ Effect of... } \\
\cline { 3 - 4 } Model \# & Career variable & Career & $\begin{array}{c}\text { Being } \\
\text { retired }\end{array}$ \\
\hline$(1)$ & in the model & & $1.123^{* *}$ \\
& None & & $(0.092)$ \\
$(2)$ & Career length & -0.017 & $1.200^{* *}$ \\
& & $(0.027)$ & $(0.155)$ \\
$(3)$ & Career earnings & -0.003 & $1.090^{* *}$ \\
& & $(0.018)$ & $(0.164)$ \\
$(4)$ & Log earnings & 0.075 & $1.052^{* *}$ \\
& & $(0.090)$ & $(0.145)$ \\
$(5)$ & Quad. earnings & 0.012 & $1.057^{* *}$ \\
& & $(0.034)$ & $(0.175)$ \\
$(6)$ & Draft round & 0.042 & $0.939^{* *}$ \\
& & $(0.047)$ & $(0.219)$ \\
\hline
\end{tabular}

Estimates are effects on the annual hazard rate multiplied by 100. Standard errors, in parentheses, are clustered by individual. The quadratic earnings effect is the average marginal effect. ** Significant at the 5 percent level.

ment increases the hazard rate by 0.00867 . Therefore, reducing the effect of retirement by one-half would require about $\$ 14$ million in additional career earnings, which is roughly 12 times the average lifetime earnings of a high school graduate (Day and Newburger, 2002).

Figure 3 shows the portion of players that have filed for bankruptcy by each year of retirement. The plot is nearly flat at zero during the 3 years before retirement, which confirms the previous finding that the hazard rate while playing is very small. (Active players don't go bankrupt.) At the beginning of retirement, the plot indicates an increasing hazard rate.

Using regression results not displayed here, we confirmed that the hazard rate increases over the course of the first two years of retirement. This 
gradual increase is likely due to a combination of players rapidly drawing down limited savings and having leveraged investments. In addition, some players continue to play professionally in another league. Football salaries are much lower outside the NFL, but these additional earnings might help players to avoid bankruptcy immediately after retirement. The hazard rate picks up as players move into retirement, and the bankruptcy proportion increases steadily up to 15.7 percent at 12 years of retirement. Beyond 12 years the estimates lose precision rapidly due to censoring because of the span of our sample.

The result of our comprehensive research on bankruptcy risk among NFL players is quite different from a widely-cited Sports Illustrated article, which reported that 78 percent of former NFL players are bankrupt or under "financial stress" within two years of retirement (Torre, 2009). After 2 years of retirement, only about 1.9 percent of players in our sample have filed for bankruptcy.

The regression analyses can be used to extrapolate the possible evolution of the bankruptcy rate later in retirement. Two prediction bounds result from estimating individual hazard rates for each year of retirement (e.g., a 9 th-year rate, an 11th-year rate, and so on). The minimum predicted hazard rate $\lambda_{\min }$ is the lowest of these estimated annual rates minus 2 standard errors. The rate $\lambda_{\max }$ is the largest estimate plus 2 standard errors. The prediction $\lambda_{t}$ is based on a regression that fits the annual hazard rate to a quadratic trend (allowing cumulative bankruptcy to level off). These results show that a very pessimistic prediction gives a bankruptcy rate of around 40 percent. However, even in the most conservative scenario nearly 15 percent of players will have declared bankruptcy by 25 years after retirement.

\section{Bankruptcy in the NFL and the general popu- lation}

Bankruptcy in the NFL sample can be compared to the general population in two ways. First, Sullivan, Thorne and Warren (2001) use court records from 
2001 to estimate simple bankruptcy filing rates. Their rates in the under 25 and 25-34 age groups are 0.0035 and 0.0117 respectively; the latter rate is close to the overall hazard rate of 0.0119 in the NFL sample even though their population's income is undoubtedly much lower. Second, the National Longitudinal Survey of Youth 1997 (NLSY) covers much the same time period as our sample. Among NLSY men in the same age cohorts as the NFL sample, the hazard rate (from self-reported bankruptcy) is $0.0038 \pm 0.0005$, which is much lower than the NFL players' rate. More analysis will done in future work to provide sharper comparisons.

\section{Conclusion}

The traditional life-cycle model of savings is put to an extreme test when workers earn a large amount of their lifetime income in a short burst which ends randomly. Players drafted by NFL teams from 1996 to 2003 are in exactly this situation. Players with median-length careers earn about $\$ 3.2$ million in a few years. If they are forward-looking and patient, they should save a large fraction of their income to provide for when they retire from the NFL.

Our findings are different from what the life-cycle model predicts. First, players declare bankruptcy relatively soon after retirement. After only two years post-retirement many players have gone into bankruptcy. Second, annual bankruptcy ("hazard") rates are not affected by a player's total earnings or career length. Having played for a long time and having been a successful and well-paid player does not provide much protection against the risk of going bankrupt.

Future work will focus on what types of players have higher bankruptcy risk, perhaps indicating behavioral biases, correlates of predictably poor financial decision making, and social variables. This evidence should also inform helpful interventions, both for these athletes and for other workers with unusual income profiles. 


\section{References}

Day, Jennifer Cheeseman, and Eric C. Newburger. 2002. The big payoff: Educational attainment and synthetic estimates of work-life earnings. US Department of Commerce, Economics and Statistics Administration, US Census Bureau Washington, DC.

Livshits, Igor, James MacGee, and Michele Tertilt. 2007. "Consumer bankruptcy: A fresh start." The American Economic Review, 97(1): 402418.

Sullivan, Teresa A., Deborah Thorne, and Elizabeth Warren. 2001. "Young, Old, and In Between: Who Files for Bankruptcy?" Norton Bankruptcy Law Advisor, 9: 1-10.

Torre, Pablo S. 2009. "How (and Why) Athletes Go Broke." Sports Illustrated. http://www.si.com/vault/2009/03/23/105789480/ how-and-why-athletes-go-broke [Accessed 1-12-2015; posted 3-292009].

Weir, David R., James S. Jackson, and Amanda Sonnega. 2009. "National Football League Player Care Foundation Study of Retired NFL Players." Ann Arbor: University of Michigan Institute for Social Research. 